\title{
The tectonic fracture modeling of an ultra-low permeability sandstone reservoir based on an outcrop analogy: A case study in the Wangyao Oilfield of Ordos Basin, China
}

\author{
Zhao Xiaoming ${ }^{1,2 *}$, Liu Li ${ }^{1}$, Hu Jialiang, Zhou Xiaojun' ${ }^{1}$ and Li Min ${ }^{4}$ \\ ${ }^{1}$ Key Laboratory of Natural Gas Geology of Sichuan Province, Southwest Petroleum University, Sichuan 610500, China \\ ${ }^{2}$ School of Geoscience and Technology, Southwest Petroleum University, Sichuan 610500, China \\ ${ }^{3}$ Abu Dhabi National Oil Company, Abu Dhabi 898, United Arab Emirates \\ ${ }^{4}$ State Key Laboratory of Oil and Gas Reservoir Geology and Exploitation, Southwest Petroleum University, Sichuan \\ 610500, China
}

(C) China University of Petroleum (Beijing) and Springer-Verlag Berlin Heidelberg 2014

\begin{abstract}
Due to inherent limits of data acquisition and geophysical data resolution, there are large uncertainties in the characterization of subsurface fractures. However, outcrop analogies can provide qualitative and quantitative information on a large number of fractures, based on which the accuracy of subsurface fracture characterization can be improved. Here we take the tectonic fracture modeling of an ultra-low permeability sandstone reservoir based on an outcrop analogy, a case study of the Chang $6_{1}{ }^{1}$ Formation of the Upper Triassic Yanchang Group of the Wangyao Oilfield in the Ordos Basin of China. An outcrop at the edge of the basin is a suitable analog for the reservoir, but the prerequisite is that they must have equivalent previous stress fields, similar final structural characteristics, relative timing and an identical depositional environment and diagenesis. The relationship among fracture density, rock type and bed thickness based on the outcrop is one of the most important fracture distribution models, and can be used to interpret fracture density in individual wells quantitatively. Fracture orientation, dip, geometry and scale, also should be described and measured in the outcrop, and can be used together with structure restoration and single well fracture density interpretation to guide fracture intensity prediction on bed surfaces and to constrain the construction of the 3D fracture geometry model of the subsurface reservoir. The application of the above principles shows the outcrop-based tectonic fracture models of the target ultra-low permeability sandstone reservoir are consistent with fractures inferred from microseismic interpretation and tracer tests. This illustrated that the fracture modeling based on the outcrop analogy is reliable and can reduce the uncertainty in stochastic fracture modeling.
\end{abstract}

Key words: Ultra-low permeability sandstone, tectonic fracture modeling, outcrop analog, subsurface reservoir, 3D modeling

\section{Introduction}

Ultra-low permeability sandstone reservoirs are those whose matrix air permeability is less than $10 \times 10^{-3} \mu \mathrm{m}^{2}(10$ $\mathrm{mD}$ ) (Zeng and Li, 2009). Because of the effect of early diagenesis and later tectonism, this kind of reservoir often has a large number of fractures (Barton et al, 1995; Luo et al, 2009; Zhang, 2003; Zeng et al, 2007). According to the origin, they can be grouped into two types, namely tectonic

*Corresponding author. email: zhxim98@163.com

Received June 24, 2013 fractures from regional tectonic stress and diagenetic fractures from intense diagenesis. However, tectonic fractures play a most important role in the seepage of ultra-low permeability sandstone reservoirs, because they control not only the fluid seepage network (Lorenz et al, 2002; Zeng, 2004; Zeng et al, 2008; Deng et al, 2011) but also the spatial extension of artificial fractures (Yuan et al, 2004; Yan et al, 2011; Hou et al, 2013). Therefore, reasonable prediction and modeling of tectonic fractures allow an assessment of water injection development for this kind reservoir, such as the water channeling direction, water content, pressure distribution, 
and reservoir production. It is an important geological basis for the development well pattern arrangement for ultra-low permeability sandstone oilfields.

However, the prediction of fractures is still a recurring worldwide challenge. The characterization and modeling of subsurface fractures in three-dimensional space is more difficult (McLennan et al, 2009; Jenkins et al, 2009; Liu et al, 2011; Deng et al, 2013). The main reason lies in limited data and the lower resolution and the difficult matching and integrating different data sets (Olson et al, 2009; Ghosh and Mitra, 2009; Hennings, 2009). Although core is the most direct, reliable, and first information which can reflect the subsurface fracture features, it is limited by the high costs of coring. Only a few wells of a reservoir have been systematically cored. Besides, cores only reflect the fracture information in a one-dimensional borehole (Belayneh et al, 2009). Reticular or board-like high angle tectonic fractures are typically not easy to drill and core in the borehole (Narr, 1991; Laubach, 2003; Laubach et al, 2004), therefore the core cannot reflect fracture information of borehole completely. This means the calibrating method of core to logging data, which is successfully applied to predicting lithology, lithofacies, and reservoir physical properties of less heterogeneity than fractures, has limitation in data matching and integration, and leads to uncertainty in fracture characterization. Conventional logging data has a lateral detection range and can reflect the characteristics of fractures around borehole, but it is limited by the vertical resolution and can only be used for qualitative evaluation of fractures, e.g. determination of the existence of fractures. Although seismic data has a high lateral resolution, its vertical resolution is often low, and this results in the challenge of fracture identification (Gauthier and Lake, 1993; Yielding et al, 1996). Especially for those ultra-low permeability reservoirs, fracture characterization is impossible directly from seismic data. There are two reasons. On the one hand, it is due to the shielding effect of thick surface loess layers which leads to the low vertical resolution of seismic data itself (Xu and Huang, 2009). On the other hand, the scale of the tectonic fractures in the study area is always too small to be detected in seismic data.

In view of the above problems of subsurface fracture characterization, this article, taking the ultra-low permeability sandstone reservoir of the Chang $6_{1}{ }^{1}$ as an example, chose an appropriate outcrop as an analogy, and carried out a detailed analysis of the outcrop fracture parameters, including fracture geometry, length, height, orientation, dip, density, and quantitative relationships between density, lithology and bed thickness. Consequently, the qualitative and quantitative fracture distribution patterns obtained from an appropriate outcrop were applied to the fracture characterization of the subsurface target reservoir. A new tectonic fracture prediction method from ground to subsurface, from single well to interwell and from qualitative to quantitative, which has certain reliability and can reduce the uncertainty of stochastic fracture modeling, is proposed in this paper.

\section{Methods}

\subsection{The analogy analysis}

An analog refers to the information selected for subsurface simulation of particular hierarchical fractures, whose resolution is sufficient to describe and measure fractures, including outcrop and physical simulation experiments. The similarity between the analog and the reservoir is a prerequisite to apply information from the analog to the subsurface fracture modeling. There are two basic principles to choose an analog, one is that the sedimentary and tectonic characteristics must be similar between the analog and the reservoir, and the most ideal analog is the outcrop of the reservoir exposed at the basin edge. Another is that the analog should have intensive sampling and the sampling density must be higher than well spacing density of the target area (Wu, 2010).

The outcrop of the target reservoir exposed at the basin edge, namely Yanhe Outcrop, is selected as the analog in this study (Fig. 1). According to the structural position, both the analog and the reservoir are located in the middle section of the Shanbei slope, Ordos Basin in China, and are in a smooth monocline with an east-to-west dip of less than $1^{\circ}$ (He, 2002). And both of them have been exposed to weak tectonic activity, and their gradient is generally $8-10 \mathrm{~m} / \mathrm{km}$ (Guo et al, 2006). Faults and folds are not developed in this area, and there are east-to-west or northeast-to-southwest low nose uplifts developed in some parts whose amplitude is only 10-20 m (Zhao, 2008). According to the sedimentary stratigraphy, both the analog and the target reservoir belong to the Chang6 Formation of the Upper Triassic Yanchang Group, and also appear to be an underwater distributary channel in a lacustrine delta front depositional system (Zhang et al, 2003; Dang et al, 2004; Guo et al, 2006; Leng et al, 2010). The sedimentary environment controls the sandbody development, and influences the type of diagenesis and physical properties of the reservoir. Both the outcrop and the reservoir experienced intense diagenesis, including compaction, carbonate cementation, feldspar dissolution, replacement, and fracturing, and are characterized by low porosity and extraordinary low permeability (Wang et al, 2012). According to the regional tectonic stress field evolution, during the Yanshan movement period (Late Triassic), due to the intense sinistral shear stress between the Pacific plate and the Eurasian plate, both experienced intense shear stress and compressive stress, and caused the northwestto-southeast compression and the northeast-to-southwest extension. During the Himalayan movement stage (Late Cretaceous-Paleogene), due to the northwards movement of the Indian plate, both experienced strong dextral shear under the effect of southwest compressional stress, and caused the northwest-to-southeast extension and the northeast-tosouthwest compression (Zhao et al, 1996).

In summary, not only the sedimentary environment and diagenesis but also the previous stress field and the final structural characteristics of the analog and the subsurface reservoir are similar. This assures similar fracture 


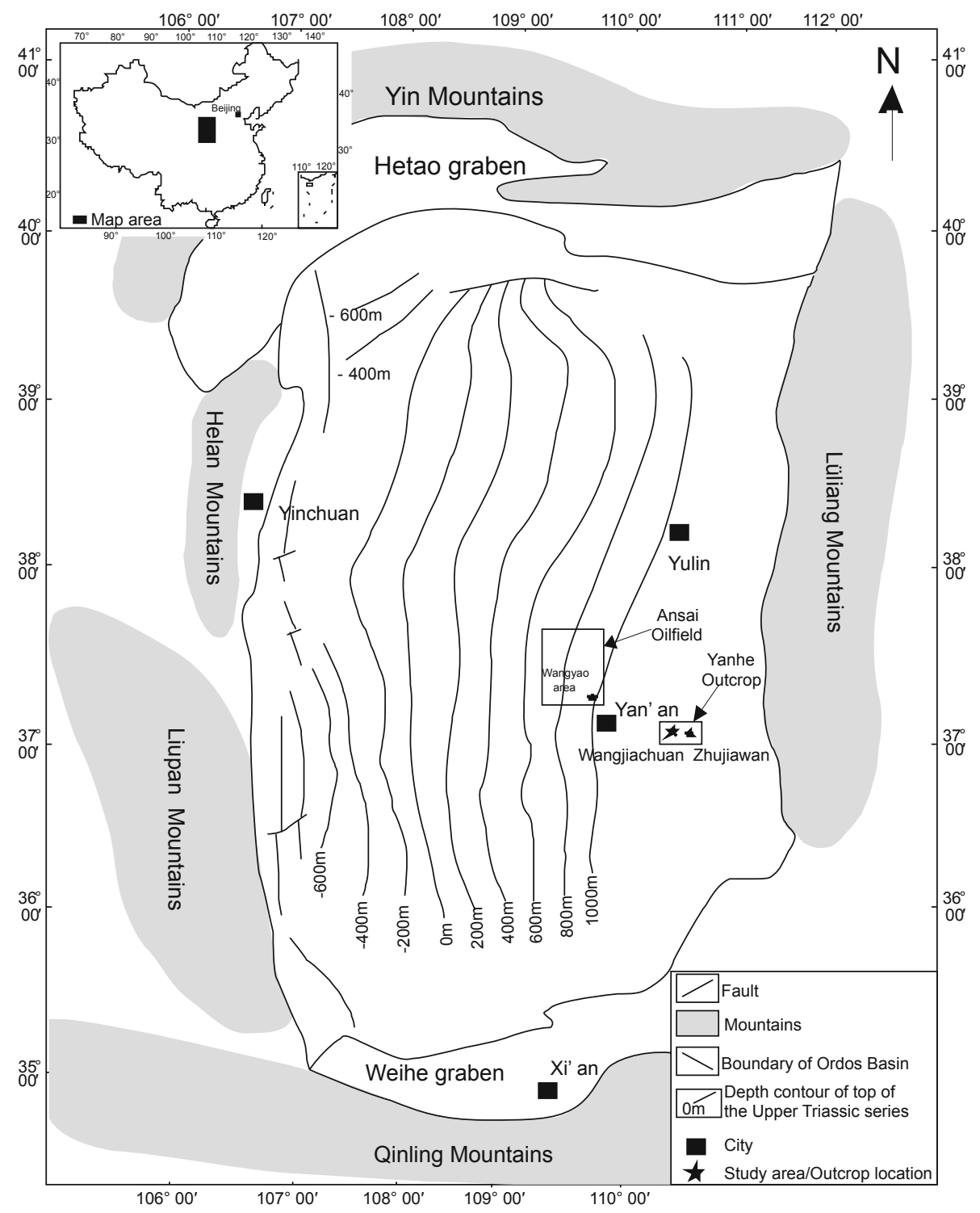

Fig. 1 Map showing the location of Ansai Oilfield and Yanhe Outcrop (Modified from Zeng and Li, 2009)

characteristics between the analog and the subsurface reservoir and lays the foundation for the subsurface tectonic fracture modeling.

\subsection{Fracture characteristics observed from outcrops}

One of the greatest advantages of outcrops is to facilitate direct observation and statistics of the fractures in twodimension (2D) or even in three-dimension (3D), providing information of lithology, bed thickness, fracture occurrences, and fracture density (Hancock, 1985; Lorenz et al, 2006). Therefore, qualitative and quantitative fracture models can be built based on outcrops which serve as the parameter knowledge base for the subsurface fracture modeling. In this study, characteristics of fracture occurrence and fracture density were first analyzed based on the Chang6 Formation from the Yanhe Outcrop in the middle section of the Ordos Basin in China.

\subsubsection{Fracture occurrences}

Fracture occurrence parameters in fracture modeling include fracture system or group, geometry, strike, dip direction, and length.

According to the statistical results of the chosen outcrop, there are four groups of fractures developed in the Chang6 Formation of the Yanchang Group, with different strikes of north-northwest (NNW), east-northeast (ENE), northeast (NE) and west-northwest (WNW) (Fig. 2). But the approximate orthogonal distribution between different groups of fractures at the same location produces a checkerboard pattern. As shown in Fig. 3, fracture geometries are rectangles observed from the 3D outcrop. According to the fracturespacing index method (Narr, 1991), fracture-spacing index values of NNW, ENE, NE and WNW fractures are 1.23, 1.13, 0.94 and 0.71 respectively. These values suggest that the fracture groups of NNW and ENE are the most developed conjugate shear fractures, followed by the conjugate shear fractures of NE and WNW. According to the observation, single fractures in the plan view can reach around 25 meters with an average length between 2 meters to 16 meters. The 


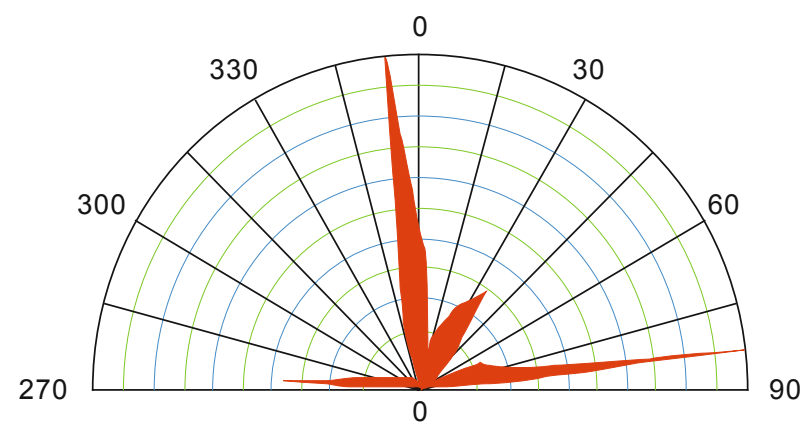

Fig. 2 Rose diagrams for fractures in the Chang6 Formation at the Yanhe Outcrop $(N=350)$
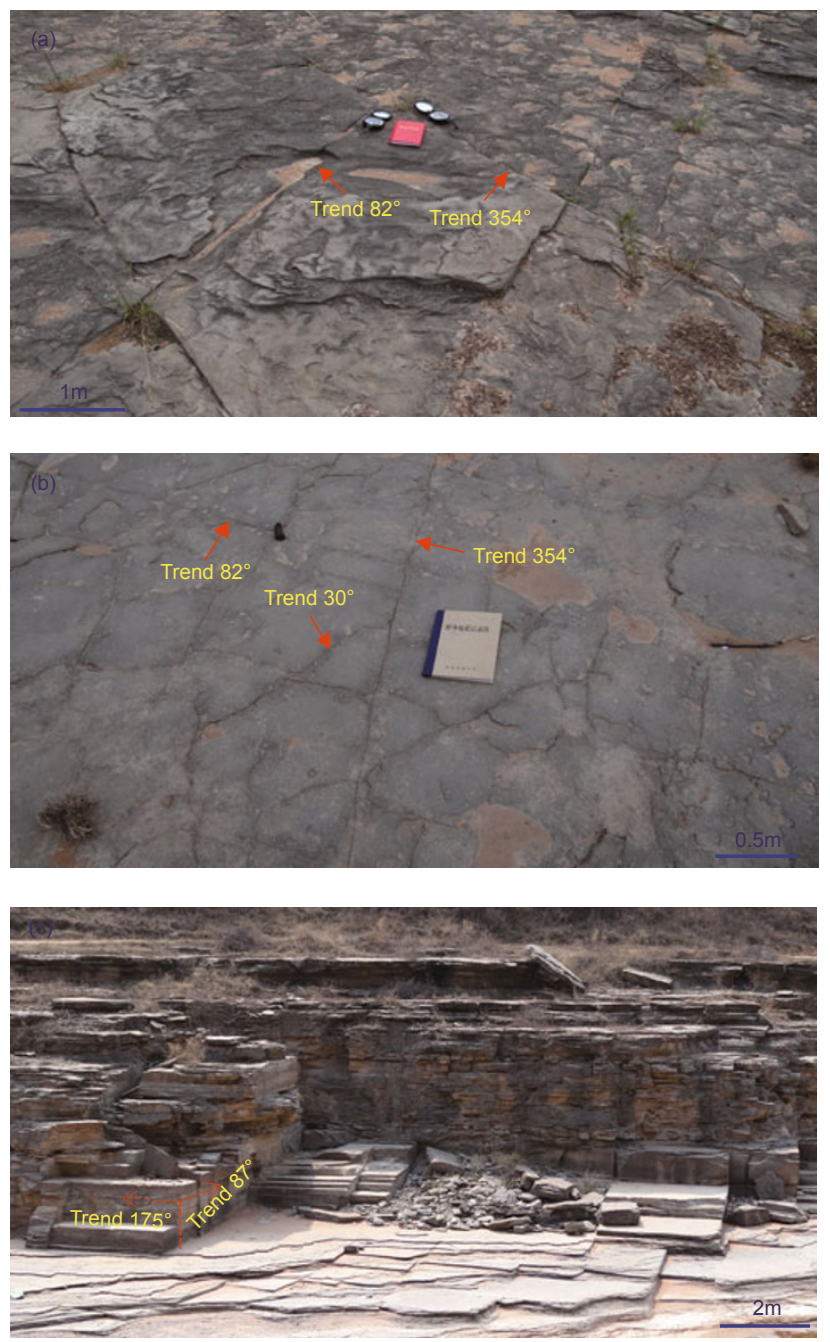

Fig. 3 Plan distribution of tectonic fractures and 3D geometry pattern in the Chang6 Formation at the Yanhe Outcrop at Zhujiawan

fracture length in the plan view varies among different lithologies, it is between 8 meters to 20 meters in fine-grained sandstones, but it decreases to 4 meters to 10 meters in siltstones.

According to the outcrop, most of the fractures developed perpendicular to the bedding, and their vertical extension is controlled by lithology. Normally, fracture height is less than $80 \mathrm{~cm}$ in fine-grained sandstones, with a maximum value of $180 \mathrm{~cm}$ and an average value of about $60 \mathrm{~cm}$ (Fig. 4(a)). In siltstones, fracture height is normally less than $40 \mathrm{~cm}$, with a maximum value of $80 \mathrm{~cm}$ and an average value of about $30 \mathrm{~cm}$ (Fig. 4(b)). Based on the statistics of the 350 fractures observed in the target formation, $86 \%$ of these fractures have a dip between $80^{\circ}$ and $90^{\circ}, 11 \%$ of them have a dip between $70^{\circ}$ and $80^{\circ}$, and $1 \%$ of them have a dip less than $10^{\circ}$ (Fig. 5). According to the classification criteria based on fracture dip, namely horizontal fractures have a dip less than $10^{\circ}$, dipping fractures have a dip between $10^{\circ}$ and $80^{\circ}$, and vertical fractures have a dip bigger than $80^{\circ}$, most of the fractures in the Chang6 Formation from the Yanhe Outcrop are vertical fractures.
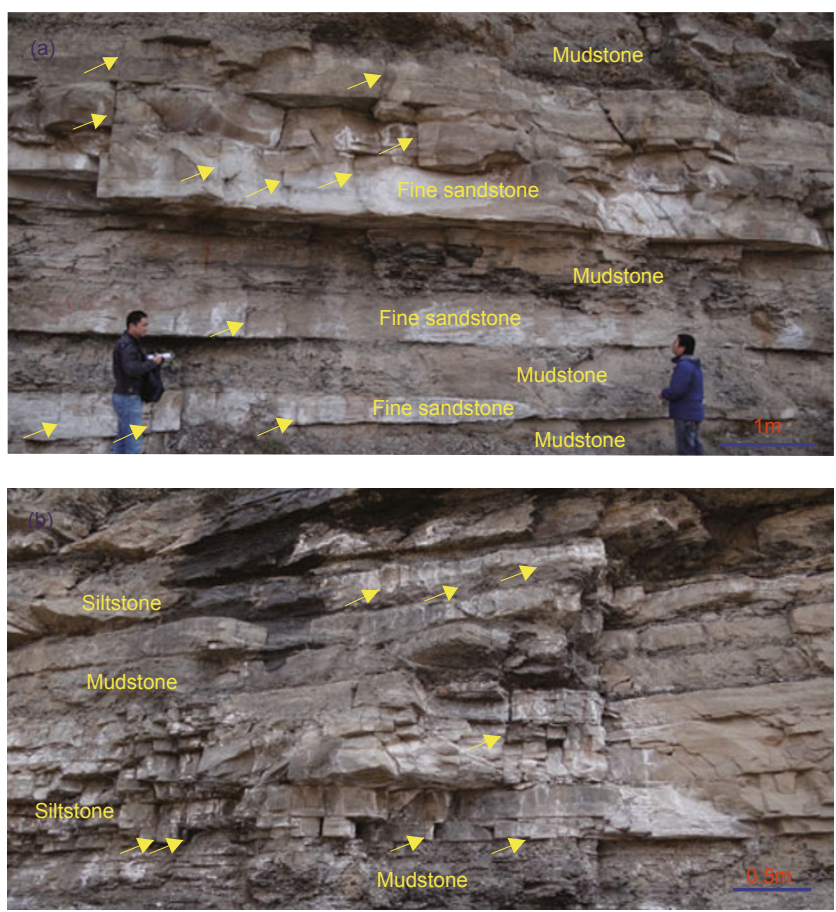

Fig. 4 Geometry pattern of tectonic fracture profile in the Chang6 Formation of the Yanhe Outcrop at Zhujiawan

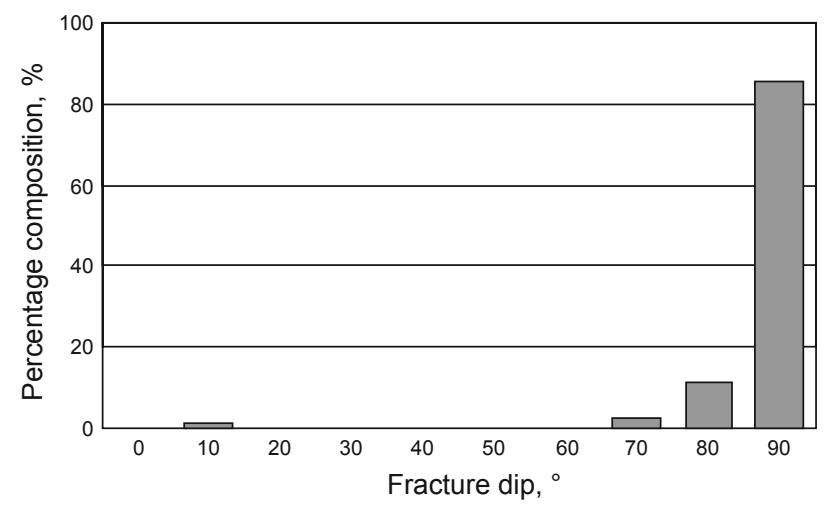

Fig. 5 Statistical histogram of tectonic fracture dip in the Chang6 Formation at the Yanhe Outcrop $(N=350)$

\subsubsection{Fracture density}

A quantitative model of fracture density distribution based on analog analysis is a key to the geometrical patterns of subsurface fractures and a traditional approach for predicting the abundance of subsurface fractures as well (Ortega et 
al, 2006). Based on the study of the relationships between fracture density and lithology as well as bed thickness of the analog Chang6 Formation, the fracture density distribution model has been established as follows.

On the one hand, fracture intensity is controlled by lithology and it is higher in sandstones than in mudstones. The mean fracture density in sandstones is $2.0 \mathrm{~m}^{-1}$, and it decreases to $0.3 \mathrm{~m}^{-1}$ in mudstones. In sandstones, fracture density increases as the content of quartz and feldspar increases, but it decreases as the grain size increases. For instance, the average fracture density in siltstones is $2.2 \mathrm{~m}^{-1}$, and it deceases to $1.6 \mathrm{~m}^{-1}$ in fine-grained sandstones. This reflects higher fracture intensity in the siltstone dominated channel flanks compared to the fine-grained sandstone dominant channels, which provides the primary geological evidence to facies-controlled fracture modeling.

On the other hand, fracture density is related with bed thickness as well. Fractures are usually developed in sandstone layers less than 1.5 meters, but seldom in sandstone layers more than 1.5 meters thick. There is a linear relationship between fracture density and bed thickness within the same lithology. As the bed thickness increases, fracture density decreases. According to the statistics of the fracture density in different lithologies of the analog, coarse-grained sediments (fine-grained sandstones and coarse-grained siltstones) and fine-grained sediments (muddy siltstones and fine-grained siltstones) have different relationships between fracture spacing and bed thickness (Fig. 6).

Coarse-grained sediments (channels):

$$
D=1.379 h-8.034
$$

Fine-grained sediments (channel flanks):

$$
D=0.398 h+9.245
$$

where $D$ is fracture spacing and $h$ is bed thickness.

According to the relationships above, under the condition of the same bed thickness, fine-grained sediments have smaller fracture spacing compared to coarse-grained sediments, which is in consistence with the previous study of the Yanchang Formation in the Ordos Basin by Zeng and Li (2009).

\subsection{Subsurface reservoir fracture modeling}

\subsubsection{Fracture density model}

\subsubsection{Well interpretation of fracture density}

In this study, lithology classification based on the core and GR log calibration was followed by fractured layer identification (namely qualitative fracture interpretation) based on conventional $\operatorname{logs}$, core and array induction log calibration. Finally, the quantitative interpretation of fracture density was studied in individual wells based on the quantitative relationships between fracture density and lithology as well as bed thickness obtained from the analog.

Because fracture intensity is related to lithology (Nelson, 1985; Narr, 1991), lithology has to be studied on individual wells. According to the core-GR log calibration and $\log$

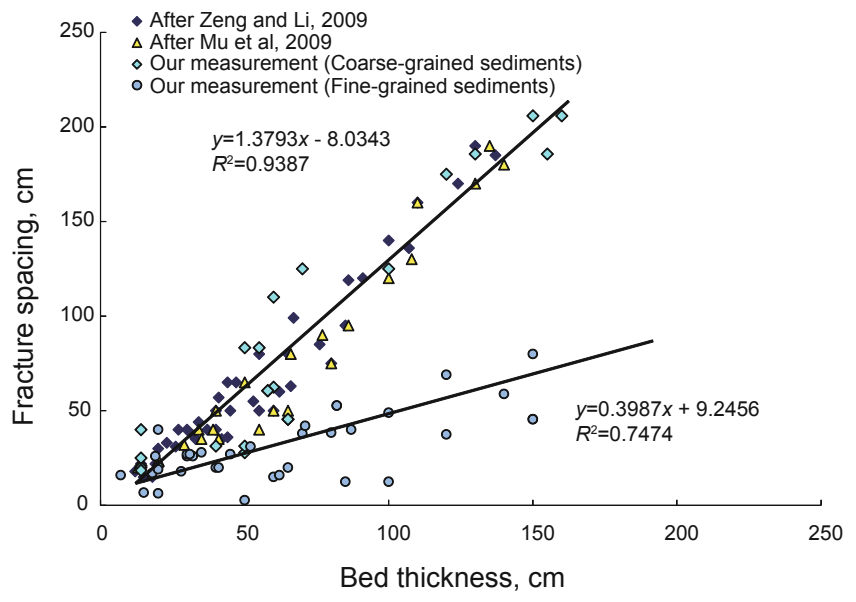

Fig. 6 Relation between fracture spacing and bed thickness of different lithologies

response analysis, different lithologies have different ranges on the GR log (Table 1). The GR value of mudstones is higher than $125 \mathrm{API}$, the GR value of muddy siltstones is between 100 API and 125 API, the GR value of fine-grained siltstones is between 85 API and 100 API, the GR value of coarse-grained siltstones is between 75 API and 85 API, and the GR value of fine-grained sandstones is lower than 75 API. Accordingly, lithology can be interpreted in fractured intervals of uncored wells.

Table 1 GR values of different lithologies

\begin{tabular}{cc}
\hline Lithology & GR value \\
\hline Mudstone & $>125$ API \\
Muddy siltstone & $100-125$ API \\
Fine-grained siltstone & $85-100$ API \\
Coarse-grained siltstone & $75-85$ API \\
Fine-grained sandstone & $<75$ API \\
\hline
\end{tabular}

Consequently, fractures were interpreted in individual wells based on lithology classification. There are some mismatches between the fracture density obtained from cores and the fracture density interpreted from logs due to limited depth of investigation, therefore there is a problem in quantitative interpretation of fracture density in individual wells by core-log calibration. But the log response of fractures can be calibrated by cores. There is a positive anomaly on an array induction $\log$, a gentle decrease compared to the country rock, where tectonic fractures have developed. As shown in Fig. 7, there is a high-angle fracture at the interval between 1,274 $\mathrm{m}$ and 1,275 $\mathrm{m}$ of coarse-grained siltstones, characterized by small aperture and semi-filled or filled. On the array induction $\log$, there is an obvious difference at the corresponding interval. On the contrary, non-fractured intervals, e.g. coarse-grained siltstone interval between $1,287 \mathrm{~m}$ and $1,288 \mathrm{~m}$, there is no clear difference on the array induction log. This indicates that fractured intervals are those with obvious difference on the 


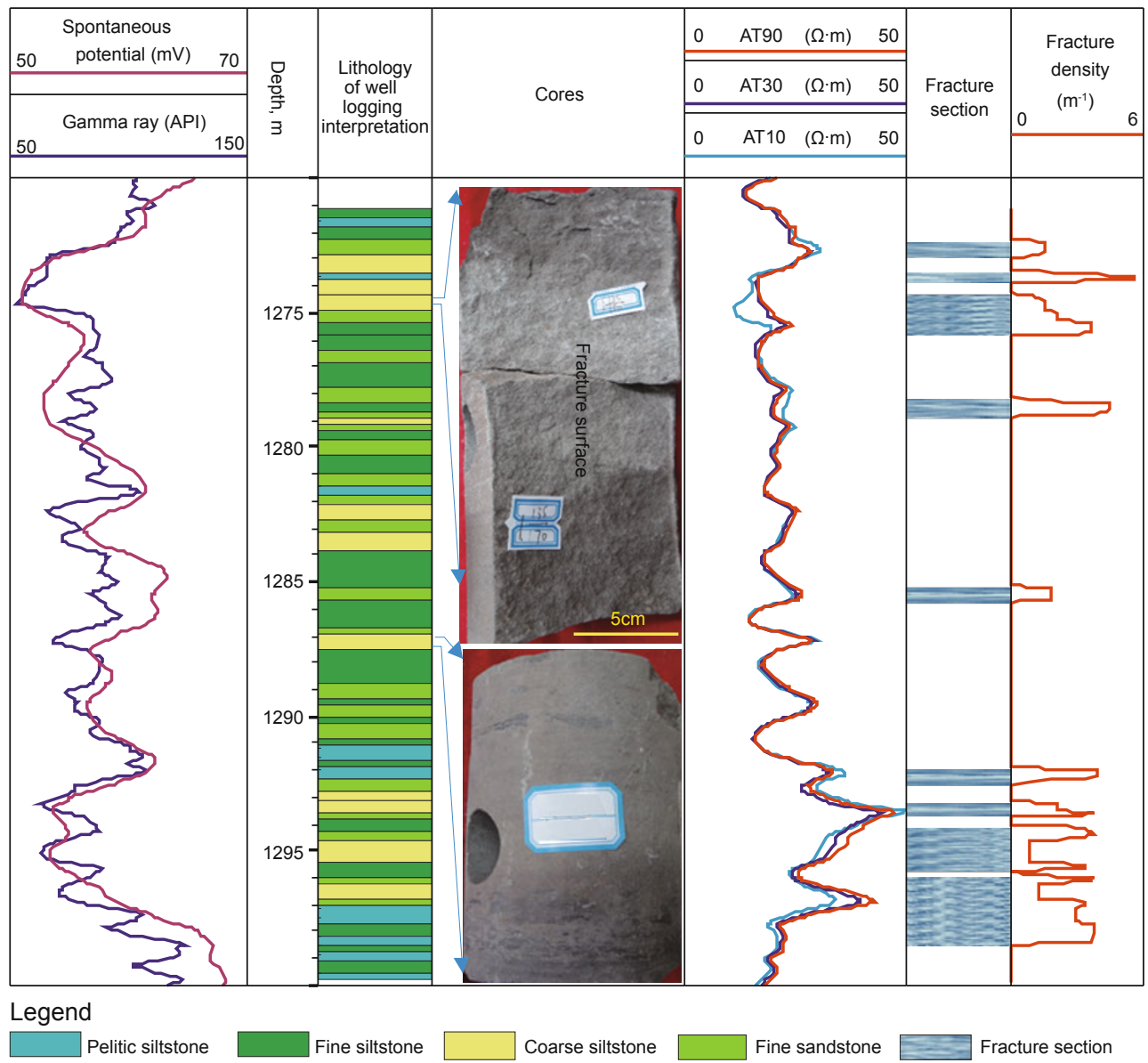

Fig. 7 Composite log of lithology, fracture qualitative and quantitative interpretation results of fracture density in the Wangyao infilling block of the Ansai Field

array induction log. Consequently, fractured intervals were interpreted qualitatively in all wells in the study area.

Fracture density in fractured intervals is interpreted quantitatively in individual wells based on the relationship between fracture spacing of different lithologies and bed thickness obtained from the analog, Eq. (1) and Eq. (2). The quantitative interpreting results of fracture density in individual wells are shown in Fig. 7.

\subsubsection{Fracture density prediction on bed surface (2d)}

First, a high-resolution 3D structural model was constructed based on well correlation. Then, tectonic parameters of each layer in the 3D structural model before and after deformation, such as stress trajectories, coefficient of expansion, Gauss curvature, and fracture fluid index, were calculated based on the tectonic reconstruction of each layer. Finally, fracture density was predicted in each layer based on a numerical model of fracture density and using fracture density results from well interpretation and tectonic parameters as variables.

High-resolution stratigraphic correlation is the basis of a high-resolution 3D structural model and a key to acquiring accurate tectonic parameters. The study area is a dense well area with mean well spacing of 150 meters which provides a solid data base for stratigraphic correlation. According to the high-resolution sequence stratigraphy method, the Chang $6{ }_{1}{ }^{1}$ fourth-order sequence was subdivided into two fifth-order sequences and nine sixth-order sequences. The average thickness of individual sixth-order sequences is less than 5 meters (Fig. 8(a)). Accordingly, high-resolution 3D structural model was established. As shown in Fig. 8(b), the study formation is a monocline tilting from east to west of simple structural geometry with local nosing structures.

After the 3D structural model was completed, the influence of the late-stage fracturing events was removed from the early-stage tectonic deformation by balanced restoration of 3D structures, namely defolding and defracturing of the deformed and fractured layers in the 3D structural model. In this way, the deformation of the sedimentary layers and the structural characteristics of tectonic events (e.g. stress field) at the early-stage of tectonic activities were restored to help interpreters understand the deformation evolution of the structural geometry and reduce the uncertainty of structural interpretation (Durand-Riard et al, 2010). Structure restoration could provide several tectonic parameters, which reflect the distribution characteristics of subsurface fractures (Lisle, 1994; Fischer and Wilkerson, 2000; Hennings et al, 2000; Griffiths et al, 2002; Maerten and Maerten, 2006; Allwardt et al, 2007). As shown in Fig. 9, according to the dilatation (quantitative index of local area variation), stress value/direction, maximum Gauss curvature $(K-\max )$, fracture developability index of the Chang $6_{1}{ }^{1-2}$ layer, fractures can be determined to be mainly distributed following directions of 

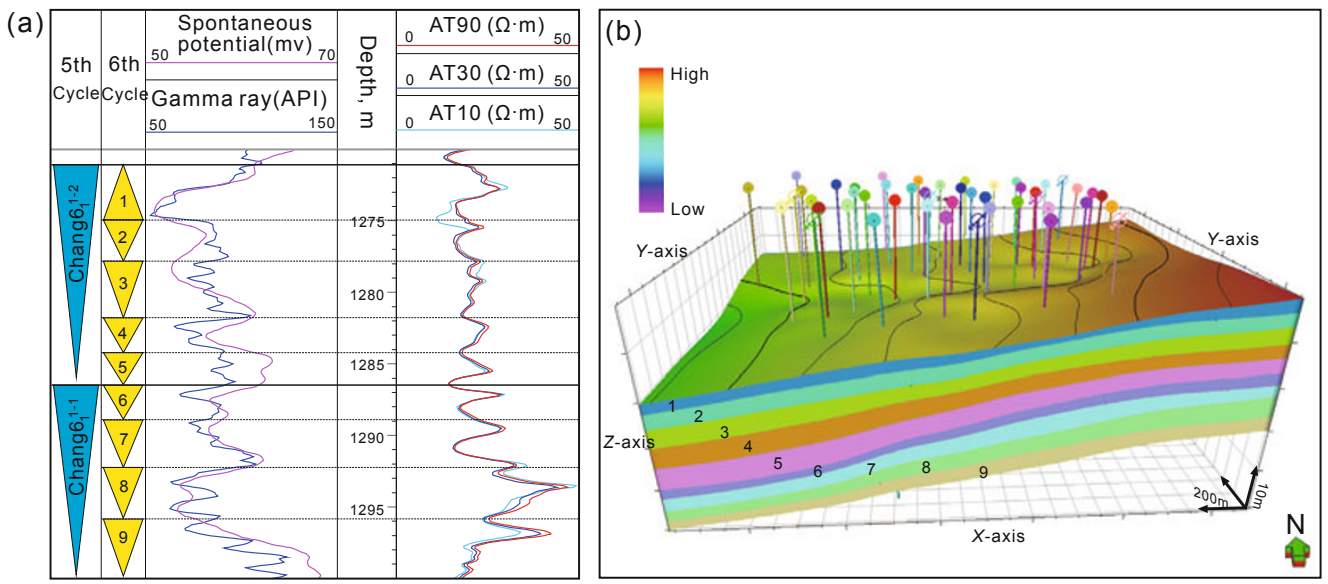

Fig. 8 Sequence classification (a) and 3D structural model (b) of the Chang $6{ }_{1}{ }^{1}$ Formation

NE, NW and EW.

The study units are sixth-order sequences in the chosen individual wells in which fractures are developed. Using the thickness-weighted average well-interpreted fracture density as the independent variable and the six tectonic parameters extracted from previous structural analysis as variables, the optimal tectonic parameters that can reflect fracture distribution were obtained based on the stepwise regression method. The basic idea of this method is to select the parameters that have the maximum efficiency based on the different importance of different parameters in each group of discriminant equations and put them into discriminant equations. On the contrary, those that have no impact on the discriminant equations are removed. In each step of this
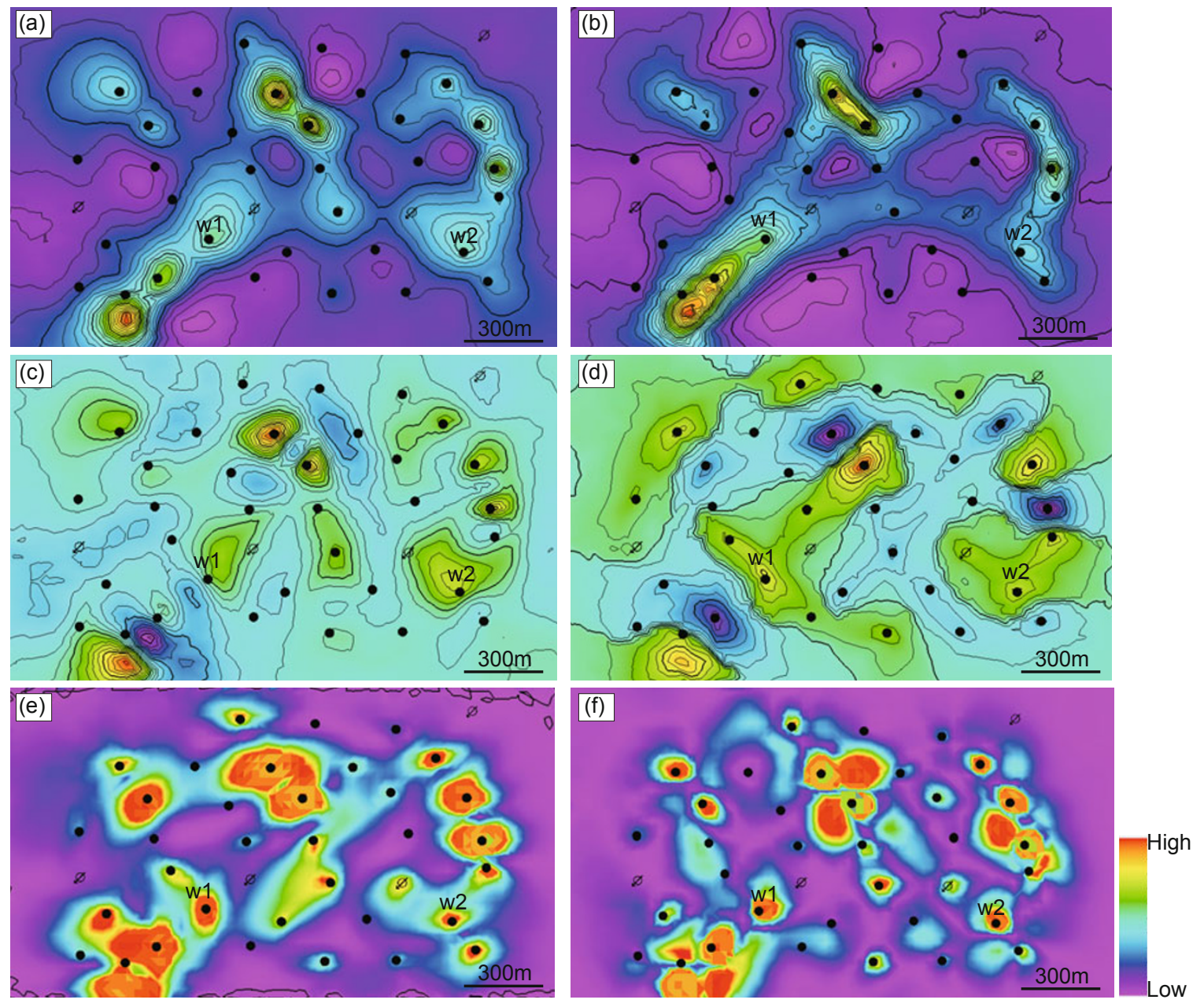

Fig. 9 Tectonic parameters of Chang $6_{1}{ }^{1-2}$, including (a) dilatation, (b) maximum strain value, (c) minimum strain value, (d) maximum Gauss curvature, (e) density, and (f) fracture developability index 
repeated process, only one parameter is considered from the first parameter to the last one. Based on the method above, the numerical model of fracture intensity using tectonic parameters as variables was established in the fractured sixthorder sequences of Chang $6_{1}^{1-2}$.

$$
\begin{aligned}
Y= & -194.465 X_{1}+1554.291 X_{2}+2953.152 X_{3}+0.009593 X_{4} \\
& +55.52436 X_{5}+0.059786 \log \left(X_{4}\right)-54.7741
\end{aligned}
$$

where $Y$ is fracture intensity, reflecting fracture density per thickness, no unit, $X_{1}$ is dilatation, $X_{2}$ is the maximum strain value, $X_{3}$ is the minimum strain value, $X_{4}$ is density, and $X_{5}$ is the developability index.

Fracture intensity of different intervals were predicted based on the tectonic parameters and the numerical model of fracture intensity. As shown in Fig. 10(a), high values of fracture intensity in Chang $6_{1}{ }^{1-2}$ range from $1 \mathrm{~m}^{-1}$ to $2 \mathrm{~m}^{-1}$, which is close to the average value of fracture intensity in fine-grained sandstones and siltstones measured from outcrop. In accord with outcrop observation, areas of high fracture intensity values are oriented NE, NW and EW as well. In addition, there is a high correlation between fracture intensity predicting results and $\log$ interpretation results of different layers (Fig. 10(b)), with a correlation coefficient of 0.93 , which proves that the inter-well fracture intensity predicting model is reliable.

\subsubsection{3D fracture density modeling}

Controlled by sedimentary facies, fracture density interpretation results from individual wells were used as solid data and fracture intensities of different layers were used as soft constraints in fracture density modeling. The sequential indicator simulation (SIS) method was applied. The final fracture density model was based on variogram models of different facies in different layers (Fig. 11).
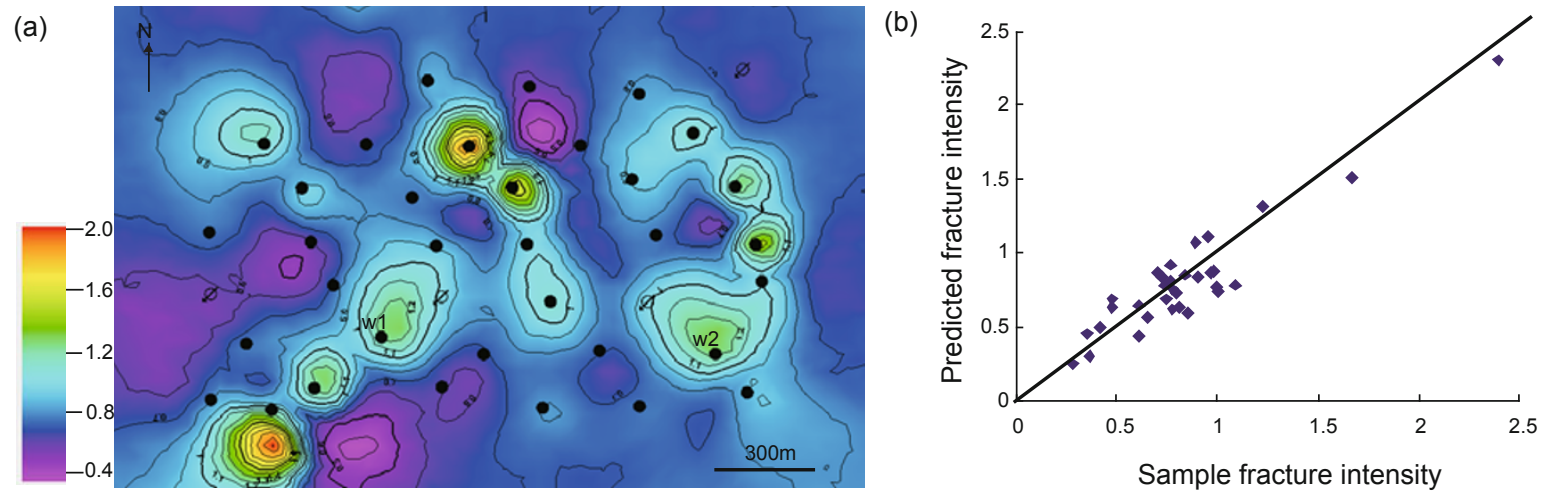

Fig. 10 Fracture intensity of Chang $6_{1}{ }^{1-2}$. (a) Inter-well predicting results of fracture intensity based on tectonic parameters. (b) Good match between fracture intensity predicting results and log interpretation results of different layers

\subsubsection{Fracture occurrence model}

Fracture occurrences include fracture strike, dip, geometry and dimension, which can be measured from the analog as discussed in the part "Fracture occurrences". Consequently, fracture strike modeling was focused in the following discussion.

Fracture strike is mainly controlled by the axis of the

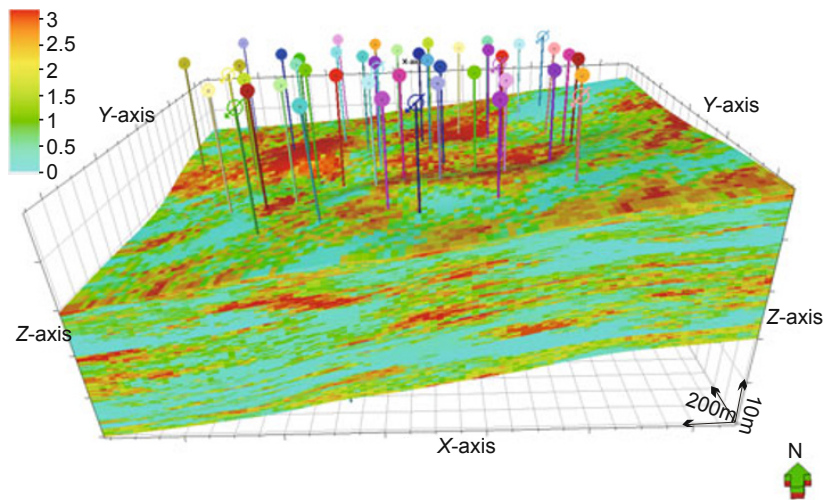

Fig. $113 \mathrm{D}$ fracture density model of Chang $6_{1}{ }^{1}$. Red color corresponds to areas of higher fracture density and blue color corresponds to areas of lower fracture density major stress, for example, the strike of open fractures is approximately perpendicular to the major stress, and the strike of shear fractures rotates 30 degrees from the major stress axis. The major stress is parallel to the maximum structural curvature. Therefore, fracture strike can be predicted from maximum curvature.

The maximum structural curvature could be calculated using a second-order deviation and Gaussian curvature analysis based on the 3D structural model as shown in Fig. 9(d) (Lisle, 1994; Rouby et al, 2000). According to the principle that the maximum curvature parallels to the major stress and the axis of major stress controls fracture strikes, fracture-flow index bar diagrams in different layers are made based on fracture analysis results from the analog. As shown in Fig. 12, fractures in the Chang $6_{1}{ }^{1-2}$ layer are distributed NNW, ENE, NE and WNW, which is consistent with the strikes observed from the outcrop. There is a difference in fracture strikes of different areas, e.g. fractures adjacent to $\mathrm{W} 1$ are dominated by NE strike but fractures adjacent to W2 are dominated by NNW and ENE strikes.

Conditioned by the fracture density model, 3D strike models of different fractures in different layers were built using an interactive determined modeling method, combining the predicted results of fracture strikes based on fracture-flow 
(a)

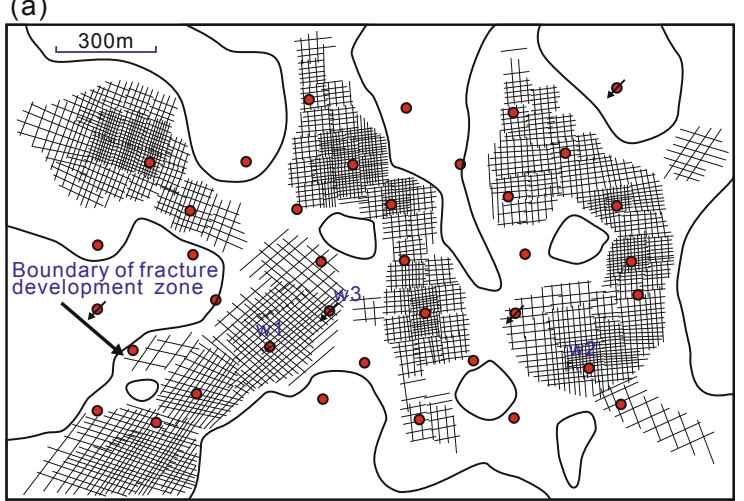

(b)

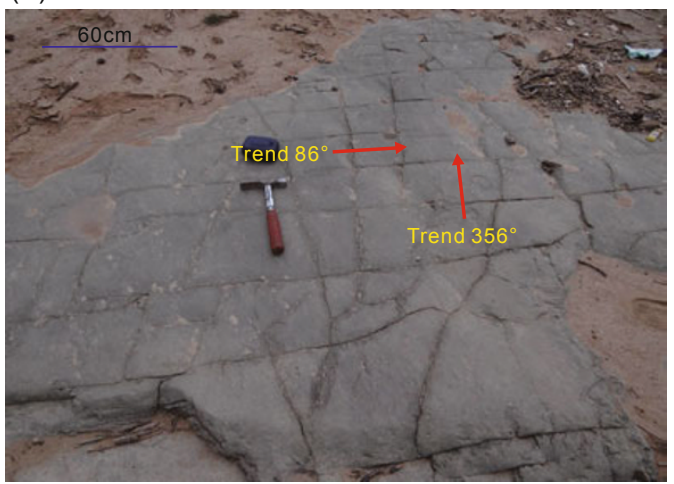

Fig. 12 FFI bar diagram of Chang $6_{1}{ }^{1-2}$. (a) Fracture strikes based on fracture intensity controlled by the fracture density model. The black curves mark the fractured area and the short lines are strikes of fractures. (b) Fracture distribution observed from the Yanhe Outcrop

index attributes in different layers. Two groups of conjugate shear fractures, NNW-ENE and WNW-NE, in Chang $6_{1}^{1-2}$ are displayed respectively in Fig. 13 .

\subsubsection{Fracture geometry model}

Fractures of the chosen formation in this study are of middle scale (tens of meters extent and less than 2 meters depth of a single fracture) according to the outcrop analysis as cited above. It is difficult to determine the location and geometry of the subsurface fractures even using high-quality seismic data, not to mention the low-quality of available seismic data due to the influence of a thick overburden of loess. However, the occurrence, density, and other attributes of the subsurface fractures could be estimated based on the statistics derived from the outcrop and from the limited samples available from subsurface reservoirs. Consequently, fracture systems or networks composed of thousands of individual fractures could be modeled using a stochastic method.

A discrete fracture network (DFN) modeling method was introduced to this study. It is an object-based stochastic modeling method, which simulates fracture systems by generating individual fractures directly in the modeling process based on the study of fracture geometries, such as fracture density, strike, dip, and scale (Dershowitz and Miller, 1995; Lange, 2009; Sam et al, 2011).

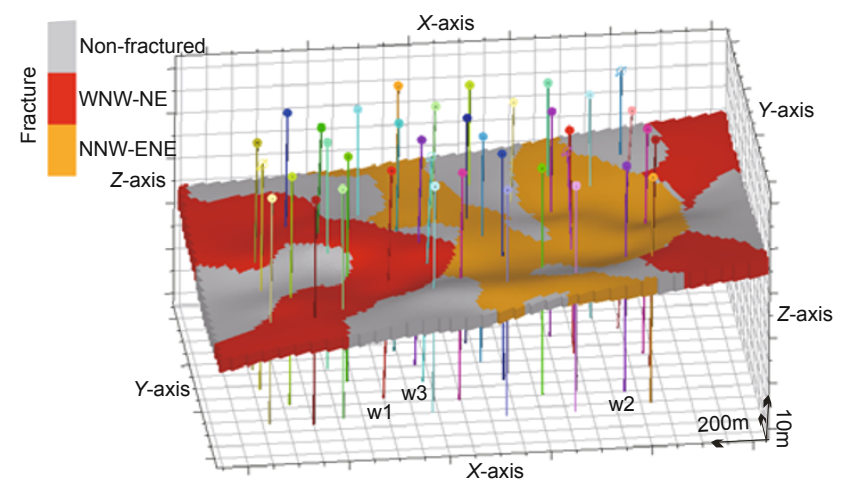

Fig. 13 Fracture development zones of Chang $6_{1}{ }^{1-2}$. Red is fractured areas of WNW-NE strike, brown is fractured areas of NNW-ENE strike, and grey is non-fractured areas
Because there are multiple groups of fractures in the study area, which vary from each other in terms of lithology (sedimentary facies), fracture density and scale, accordingly fracture models were built for the different fracture groups. For instance, the subsurface fracture geometry model was built with the DFN stochastic method, using fracture dip, geometry and scale measured from the analog as solid data and the fracture density model as a soft constraint, conditioned to the sedimentary facies model and fracture strike model. The networks of different fracture systems in the chosen formation are shown in Fig. 14. The fracture density and occurrence of the modeling results are consistent with those observed from the outcrop.

\section{Results}

The reliability of the resulting 3D fracture model, was checked using the rock mechanical data from the oil field and by micro seismic data from fractured wells.

According to the rock mechanical data, the shear strength of fine-grained sandstones is between $42 \mathrm{MPa}$ and $69 \mathrm{MPa}$ under $10 \mathrm{MPa}$ confining pressure (Zhang, 2007). Because tectonic fractures can only develop when the loading pressure is no more than $80 \%$ of the rock compressive strength, the breakdown pressure of fine-grained sandstones without fractures is about $34 \mathrm{MPa}$ to $56 \mathrm{MPa}$. Normally, the breakdown pressure in the study area is less than $28 \mathrm{MPa}$ during fracturing, which indicates that tectonic fracturing is an important factor controlling the distribution of artificial fractures. For instance, artificial fractures are mainly developed and distributed along the natural tectonic fractures, which is the base to observe subsurface tectonic fractures from micro seismic data.

According to Mohr-Coulomb theory, micro seismic activity normally occurs along the existing fracture surfaces. The outline of subsurface fractures can be characterized by recording these micro seismic events and locating their sources (Pater et al, 2001; Ge, 2005; Maxwell and Urbancic, 2001). During hydraulic fracturing, rocks are broken, and fractures are formed where there were natural fractures previously. Spreading micro seismic signals are generated during lateral expansion of fractures and can be recorded by 
(a)

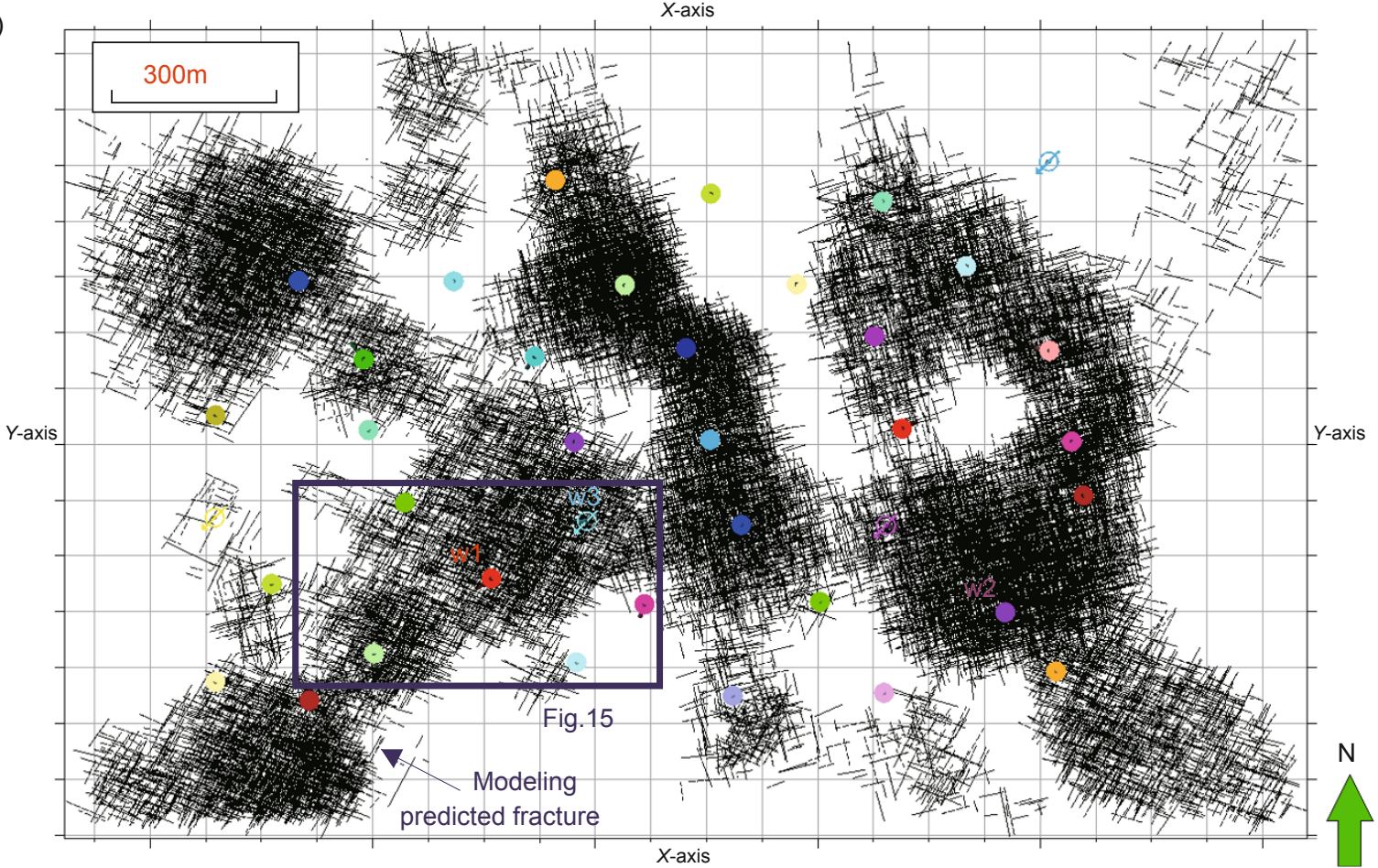

(b)

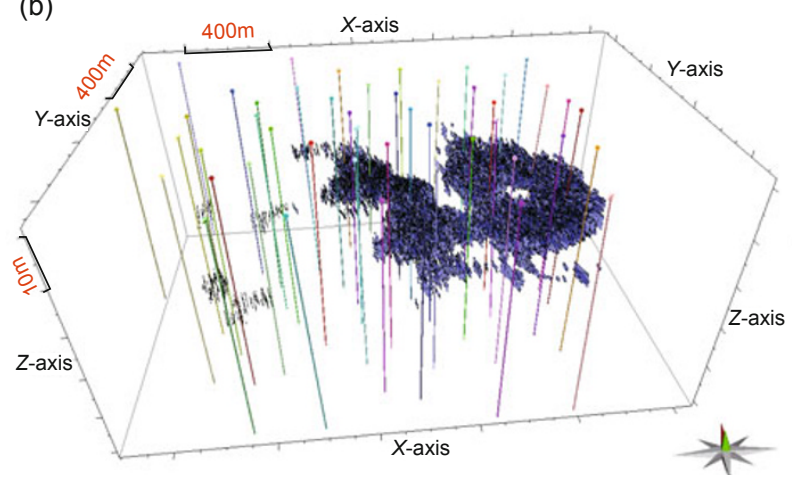

(d)

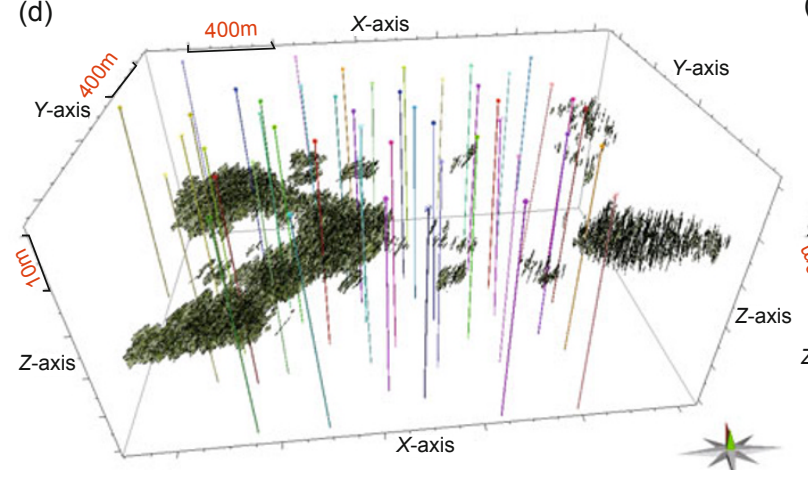

(c)

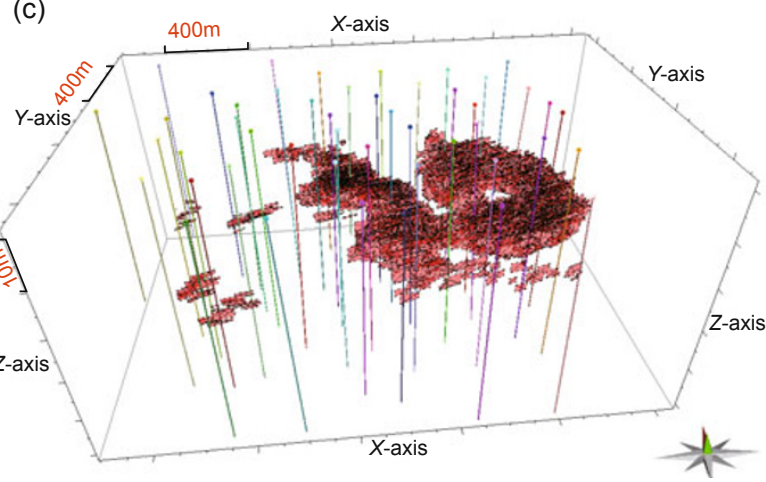

(e) $\quad 400 \mathrm{~m} \quad x$-axis

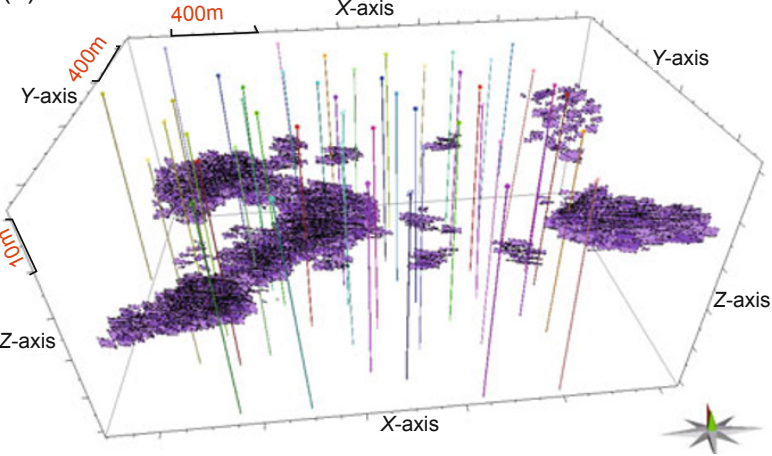

Fig. 14 Fracture geometry model of Chang $6_{1}{ }^{1-2}$. (a) Plan distribution of simulated fractures; (b) Distribution of NNW fractures; (c) Distribution of ENE fractures; (d) Distribution of NE fractures; (e) Distribution of WNW fractures

monitoring stations adjacent to the monitoring wells. A series of function groups are generated based on the time records of different monitoring stations, and the sources of the micro seismic activity can be located by solving these function groups. As a consequence, the general condition of subsurface fractures can be estimated by integrating the micro seismic source locations.

According to the micro-seismic data, the modeling can properly reflect the development of subsurface fractures. As shown in Fig. 15, the monitoring record of well W1 during fracturing lasts 84 minutes $(5,040 \mathrm{~s})$. The breakdown pressure during fracturing is $27.5 \mathrm{MPa}$ which is far smaller than the breakdown pressure of fine-grained sandstones without fractures. This indicates that natural fractures are developed adjacent to this well, which matches the simulation results that fractures are well developed in this well. In addition, 
subsurface fractures and their orientations can be mapped by connecting the sample points of close micro seismic sources and similar record time, as the adjacent points of similar color in the following figure, based on the analysis of micro seismic sources and their locations in plan view. As shown in Fig. 15 , fractures around well $\mathrm{W} 1$ are dominated by WNW and NE conjugate shear fractures, which is consistent with the modeling result.

Furthermore, tracer tests of W3 well show that the NE and WNW fractures have better connectivity than others, whose average velocity of tracer movement are $27 \mathrm{~m} / \mathrm{d}$ and $36 \mathrm{~m} / \mathrm{d}$ separately, but the others are smaller than $10 \mathrm{~m} / \mathrm{d}$. These are in accordance with the fracture distribution prediction of the modeling. Thus the model is relatively reliable.

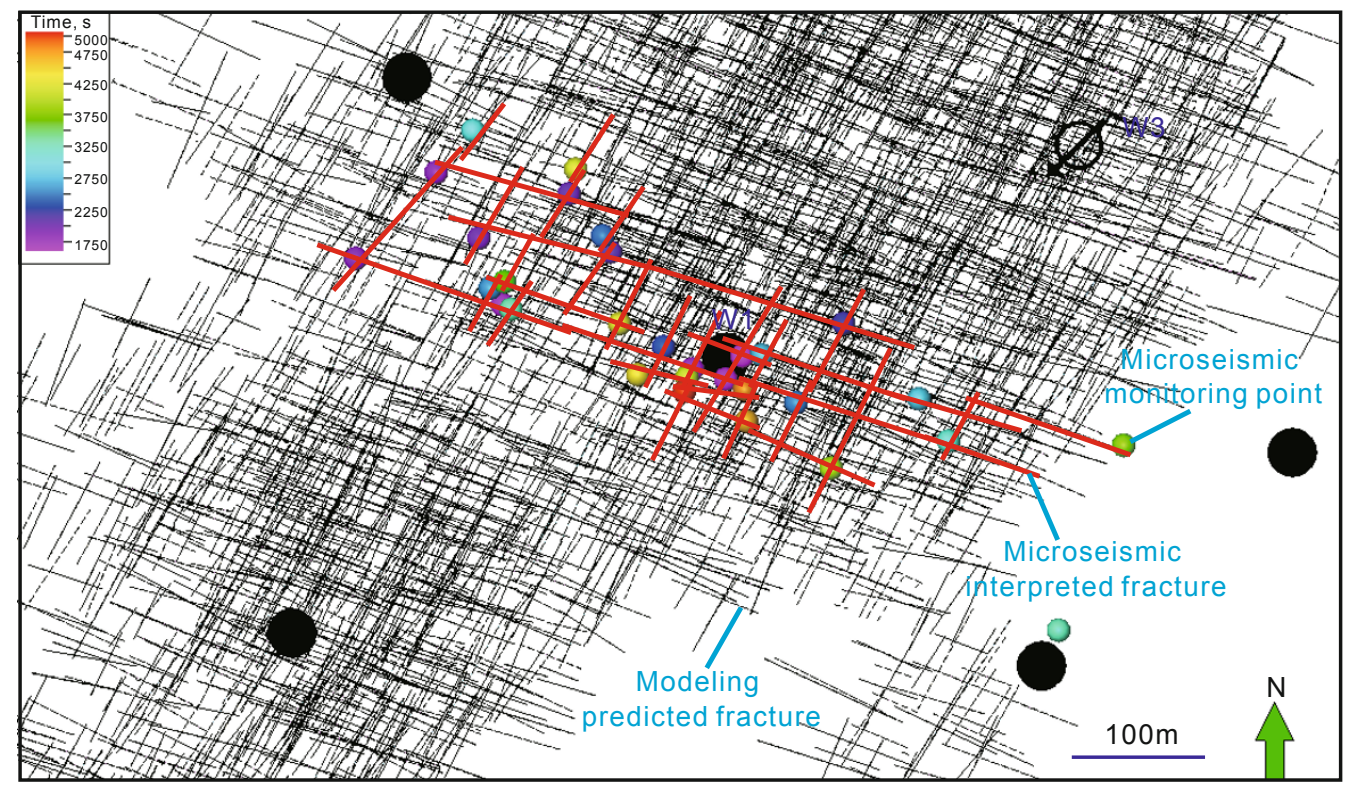

Fig. 15 Comparison between fracture geometry model and fracture prediction results based on micro seismic data from Chang $6_{1}{ }^{1}$. Red lines represent fracture prediction results based on micro seismic data, black lines represent fracture modeling results, and the color points represent the source locations of micro seismic events recorded at different time

\section{Discussion}

Although the fracture study of the analogy outcrop can improve the accuracy of subsurface fracture characterization, some factors must be considered in the actual practice.

The analogy outcrop, affected by weathering, surface water erosion, human activities, may develop fractures from a new stress field, and in this condition, the outcrop fracture parameters may deviate from the subsurface. For instance, strong weathering of the outcrop which is absent in the subsurface may exaggerate the fracture density of some hard formation but obscure that of soft ones. Therefore, we should know how to discriminate the above induced fractures. Generally, original tectonic fractures are regular and stable in occurrence and appear in groups; while those formed by secondary geological process are characterized by massive chaotic distribution, short extension, opening and not mineral filled.

Pressure from surrounding rocks can also lead to inaccurate fracture parameters of the outcrop. The same rock bed from the outcrop and corresponding subsurface reservoir may behavior totally different in mechanical properties due to the overburden pressure. Because of the tectonic uplift, some fractures may be open or developed by the release of stress (Zhou et al, 2005). Therefore, some fracture parameters obtained from the outcrop, such as aperture, have little indication for the tectonic fracture modeling in the reservoir.
In addition, one should be very careful in applying those parameters to a reservoir buried in deeper formation.

Tectonic position can also make fracture parameters different. Fracture extension and orientation, especially for tectonic fracture, may be different due to different dimension and direction of stress field in different tectonic positions ( $\mathrm{Li}$ et al, 2013). For example, fracture density in the axial and plunging flank of a fold is higher than the limbs, as curvature of the former is much higher so a higher stress concentration is developed. And in adjacent to faults, fracture distribution is segmented due to stress segmentation, and in most cases fracture density in the hanging wall is higher than that in the foot wall. Therefore, the tectonic position of an outcrop analog should be fully considered, and it is better to choose one developed in a similar tectonic location to the reservoir.

As well, the core from an ultra-low permeability sandstone may produce artificial fractures owing to rock mechanical properties and to impact of the drilling bit during coring, thus natural and artificial fractures should be distinguished during the core description. Normally, artificial fractures develop a petal pattern around the core axis and rotate to the edge.

In brief, various factors, including tectonic position, weathering, sedimentary environment, diagenetic process, and reservoir burial depth, should be taken into account in choosing an appropriate outcrop analogy. Fractures from the original stress and from secondary geological processes must be differentiated during the outcrop description. Only in 
this way, can uncertainty of subsurface fracture modeling be reasonably reduced.

\section{Conclusions}

Although the abundant qualitative and quantitative information from the outcrop analog significantly improved the accuracy of subsurface fracture characterization, the prerequisite for this is to choose an appropriate outcrop. Two criteria identify appropriate outcrops. One is the structural, sedimentary and diagenesis similarity of the outcrop to the subsurface reservoir, including similarity in the degree and timing of diagenetic alteration and timing of fracturing. The other is sufficient exposure to allow intensive sampling leading to a higher sampling density than the well density in the study area. An optimal analog is an outcrop corresponding to the subsurface oil field at the edge of the basin.

In fact, the key to fracture characterization from outcrop to subsurface reservoir is to match and integrate information among outcrop, core, logging, and stratigraphy data. The linear relationship between fracture density in different rock types and bed thickness obtained from the outcrop can be used in quantitative interpretation of subsurface fracture density of the fractured intervals in individual wells. This method solves the information mismatch between the fracture density described from cores and the log data with limited depth of investigation, and improves the accuracy of subsurface fracture density model. The fracture strike, dip, geometry, length, fracture depth and other parameters obtained from the outcrop can be used in fracture prediction based on structural restoration and constraining the $3 \mathrm{D}$ fracture occurrence model of the subsurface reservoir.

For the ultra-low permeability sandstone reservoir in the study area covered by thick loess, the fractures are of middle scale (tens of meters extent and less than 2 meters depth of a single fracture) and hardly have a detectible seismic response. Inter-well fracture characterization is mainly based on structural restoration in this study. Therefore, highresolution sequence framework is the basis for improving the accuracy of fracture prediction. Besides, because fracture intensity is mainly controlled by lithology and bed thickness, a sedimentary facies model has to be built to constrain fracture modeling. Furthermore, the introduction of outcrop information to subsurface study is the key to reducing the uncertainty of stochastic modeling of subsurface fractures in ultra-low permeability sandstone reservoirs.

\section{Acknowledgements}

The authors are extremely grateful to Gao Chunning, Zhang Jiaosheng, Liu Ping senior engineers from the Changqing Oil and Gas Field Branch, PetroChina Company Limited (PCL); Chen Wei, Tang Hong, and Xie Lin, teachers and students from the Southwest Petroleum University, for their generous help and constructive suggestions. The authors are particularly grateful to the reviewers and editors of this paper. This study is financially supported by Open Fund (PLC201203) of State Key Laboratory of Oil and Gas Reservoir Geology and Exploitation (Chengdu University of Technology), and Major Project of Education Department in
Sichuan Province (13ZA0177); and we greatly appreciated the support.

\section{References}

Allwardt P F N, Bellahsen N, and Pollard D D. Curvature and fracturing based on global positioning system data collected at Sheep Mountain anticline, Wyoming. Geosphere. 2007. 3(6): 408-421

Barton C A, Zoback M D and Moos D. Fluid flow along potentially active faults in crystalline rock. Geology. 1995. 23(8): 683-686

Belayneh M W, Matthäi S K, Blunt M J, et al. Comparison of deterministic with stochastic fracture models in water-flooding numerical simulations. AAPG Bulletin. 2009. 93(11): 1633-1648

Dang B, Zhao H, Li W H, et al. Characteristic of sedimentary microfacies in Chang 6 oil-bearing formation of Yanchang Formation of Ansai oil field. Natural Gas Geoscience. 2004. 15(6): 597-600 (in Chinese)

Deng S G, Fan Y R, Li Z Q, et al. Response characteristics of array lateral logs and their primary inversion in reservoirs with fractureinduced anisotropy. Petroleum Science. 2011. 8(1): 11-16

Deng S G, Wang Y, Hu Y Y, et al. Integrated petrophysical log characterization for tight carbonate reservoir effectiveness: A case study from the Longgang area, Sichuan Basin, China. Petroleum Science. 2013. 10(3): 336-346

Dershowitz B and Miller I. Dual porosity fracture flow and transport. Geophysical Research Letters. 1995. 22(11): 1441-1444

Durand-Riard P, Caumon G and Muron P. Balanced restoration of geological volumes using relaxed meshing constraints. Computers and Geosciences. 2010. 36(4): 441-452

Fischer M P and Wilkerson M S. Predicting the orientation of joints from fold shape: Results of pseudo-three-dimensional modeling and curvature analysis. Geology. 2000. 28(1): 15-18

Gauthier B D M and Lake S D. Probabilistic modeling of faults below the limit of seismic resolution in Pelican field, North Sea, offshore United Kingdom. AAPG Bulletin. 1993. 77(5): 761-777

Ge M C. Efficient mine microseismic monitoring. International Journal of Coal Geology. 2005. 64(1/2): 44-56

Ghosh K and Mitra S. Structural controls of fracture orientations, intensity, and connectivity, Teton anticline, Sawtooth Range, Montana. AAPG Bulletin. 2009. 93(8): 995-1014

Griffiths P, Jones S, Salter N, et al. A new technique for 3-D flexuralslip restoration in fault-related folds: The transition from 2-D to 3-D. Journal of Structural Geology. 2002. 24(4): 773-782

Guo Y Q, Li W H, Chen Q H, et al. Oil accumulation factors of Chang 6 oil reservoir of Yanchang Formation of Upper Triassic in Ansai Oilfield. Journal of Northwest University (Natural Science Edition). 2006. 36(4): 639-642 (in Chinese)

Hancock P L. Brittle microtectonics: principles and practice. Journal of Structural Geology. 1985. 7(3-4): 437-457

He Z X. The Tectonic Evolution and Petroleum in the Ordos Basin. Beijing: Petroleum Industry Press. 2002. 390 (in Chinese)

Hennings P H, Olson J E and Thompson L B. Combining outcrop data and three-dimensional structural models to characterize fractured reservoirs: An example from Wyoming. AAPG Bulletin. 2000. 84(6): 830-849

Hennings P. AAPG-SPE-SEG Hedberg research conference on "The Geologic Occurrence and Hydraulic Significance of Fractures in Reservoirs". AAPG Bulletin. 2009. 93(11): 1407-1412

Hou B, Chen M, Wang Z, et al. Hydraulic fracture initiation theory for a horizontal well in a coal seam. Petroleum Science. 2013. 10(2): 219225

Jenkins C, Ouenes A, Zellou A, et al. Quantifying and predicting naturally fractured reservoir behavior with continuous fracture models. AAPG Bulletin. 2009. 93(11): 1597-1608 
Lange A G. Assisted history matching for the characterization of fractured reservoirs. AAPG Bulletin. 2009. 93(11): 1609-1619

Laubach S E. Practical approaches to identifying sealed and open fractures. AAPG Bulletin. 2003. 87(4): 561-579

Laubach S E, Reed R M, Olson J E, et al. Coevolution of crackseal texture and fracture porosity in sedimentary rocks: Cathodoluminescence observations of regional fractures. Journal of Structural Geology. 2004. 26(5): 967-982

Leng D F, Wang X J, Chen T S, et al. Sedimentary microfacies and hydrocarbon distribution in the lower member of the Chang- 6 oil measures in the Wangyao-Houshui-Xinghe-Pingqiao zone, Ansai OilField, Shaanxi. Sedimentary Geology and Tethyan Geology. 2010. 30(1): $49-53$ (in Chinese)

Li M, Jiang B, Lin S F, et al. Structural controls on coalbed methane reservoirs in Faer Coal Mine, Southwest China. Journal of Earth Science. 2013. 24(3): 437-448

Lisle R J. Detection of zones of abnormal strains in structures using Gaussian curvature analysis. AAPG Bulletin. 1994. 78(12): 18111819

Liu L F, Sam Z D, Yang H J, et al. Seismic attributes and integrated prediction of fractured and caved carbonate reservoirs in the Tarim Basin, China. Petroleum Science. 2011. 8(4): 455-461

Lorenz J C, Cooper S P and Olsson W A. Natural fracture distributions in sinuous, channel-fill sandstones of the Cedar Mountain Formation, Utah. AAPG Bulletin. 2006. 90(9): 1293-1308

Lorenz J C, Sterling J L, Schechter D S, et al. Natural fractures in the Spraberry Formation, Midland Basin, Texas: The effects of mechanical stratigraphy on fracture variability and reservoir behavior. AAPG Bulletin. 2002. 86(3): 505-524

Luo J L, Morad S, Salem A, et al. Impact of diagenesis and reservoir quality evolution in fluvial and lacustrine-deltaic sandstones: evidence from Jurassic and Triassic sandstones from the Ordos Basin, China. Journal of Petroleum Geology. 2009. 32(1): 79-102

Maerten L and Maerten F. Chronologic modeling of faulted and fractured reservoirs using geomechanically based restoration: Technique and industry applications. AAPG Bulletin. 2006. 90(8): 1201-1226

Maxwell S C and Urbancic T I. The role of passive microseismic monitoring in the instrumented oil field. SPE Reservoir Evaluation \& Engineering. 2001. 20(6): 636-639

McLennan J A, Allwardt P F, Hennings P H, et al. Multivariate fracture intensity prediction: Application to Oil Mountain anticline, Wyoming. AAPG Bulletin. 2009. 93(11): 1585-1595

Mu L X, Zhao G L, Tian Z Y, et al. Reservoir Fractures Prediction. Beijing: Petroleum Industry Press. 2009. 83 (in Chinese)

Narr W. Fracture density in the deep subsurface: Techniques with application to Point Arguello oil field. AAPG Bulletin. 1991. 75(8): 1300-1323

Nelson R A. Geologic Analysis of Naturally Fractured Reservoirs. Houston: Gulf Publishing Company. 1985. 12-17

Olson J E, Laubach S E and Lander R H. Natural fracture characterization in tight gas sandstones: Integrating mechanics and diagenesis. AAPG Bulletin. 2009. 93(11): 1535-1549

Ortega R J, Marrett R A and Laubach S E. A scale-independent approach to fracture intensity and average spacing measurement. AAPG Bulletin. 2006. 90(2): 193-208

Pater C J, Groenenboom J, Dam D B, et al. Active seismic monitoring of hydraulic fractures in laboratory experiments. International Journal of Rock Mechanics and Mining Sciences. 2001. 38(6): 777-785

Rouby D, Xiao H and Suppe J. 3-D restoration of complexly folded and faulted surfaces using multiple unfolding mechanisms. AAPG Bulletin. 2000. 84(6): 805-829

Sam Z S, Zhou X Y, Yang H J, et al. Fractured reservoir modeling by discrete fracture network and seismic modeling in the Tarim Basin, China. Petroleum Science. 2011. 8(4): 433-445

Wang L, Li W H, Lin T, et al. Diagenesis and its influencing factors of Chang6 interval of Upper Triassic Yanchang Formation in Ordos Basin. Journal of Palaeogeography. 2012. 14(3): 311-320 (in Chinese)

Wu S H. Reservoir Characterization and Modeling. Beijing: Petroleum Industry Press. 2010. 163 (in Chinese)

Xu C Q and Huang X. Research on seismic field data acquisition method in loess tableland ravine area. Coal Geology of China. 2009. 21(2): 70-74 (in Chinese)

Yan T, Li W and Bi X L. An experimental study of fracture initiation mechanisms during hydraulic fracturing. Petroleum Science. 2011. 8(1): 87-92

Yielding G, Needham T and Jones H. Sampling of fault populations using sub-surface data: A review. Journal of Structural Geology. 1996. 18(2-3): 135-146

Yuan S Y, Song X M and Ran Q Q. Development Technology of Fractured Reservoirs. Beijing: Petroleum Industry Press. 2004. 336 (in Chinese)

Zeng L B. A study of fracture and its seepage characteristics in lowpermeability sandstone reservoirs. Scientia Geologica Sinica. 2004. 39(1): 11-17 (in Chinese)

Zeng L B, Gao C Y, Qi J F, et al. The distribution rule and seepage effect of the fractures in the ultra-low permeability sandstone reservoir in east Gansu Province, Ordos Basin. Science in China (Series D: Earth Sciences). 2008. 51(Supp. II): 44-52

Zeng L B and Li X Y. Fractures in sandstone reservoirs with ultralow permeability: A case study of the Upper Triassic Yanchang Formation in the Ordos Basin, China. AAPG Bulletin. 2009. 93(4): 461-477

Zeng L B, Li Z X, Shi C E, et al. Characteristics and origin of fractures in the sandstone reservoirs of ultra-low permeability of the Upper Triassic Yanchang Formation in the Ordos Basin. Acta Geologica Sinica. 2007. 81(2): 174-180 (in Chinese)

Zhang C M, He Z M, Wang Z Q, et al. Non-flattening delta front sheet sand-Evidence from outcrops and subsurface. Journal of Jianghan Petroleum Institute. 2003. 25(3): 1-4 (in Chinese)

Zhang L. Characteristics of reservoir fracture and the analysis of stress field in Shaanxi-Gansu-Ningxia Basin. Geological Science and Technology Information. 2003. 22(2): 21-24 (in Chinese)

Zhang Y L. Distribution and predication of tectonic fracture for Chang6 reservoir in Yanhewan explorative area in Ansai Oilfield [Ms.D thesis]. Beijing, Chinese Academy of Geological Sciences. 2007. 2123 (in Chinese)

Zhao M W, Behr H J, Ahrendt H, et al. Thermal and tectonic history of the Ordos Basin, China: evidence from apatite fission track analysis, vitrinite reflectance, and K-Ar dating. AAPG Bulletin. 1996. 80(7): 1110-1134

Zhao W B. Study on reservoir features and fracture of Yanchang Formation, Triassic in the central region of Ordos Basin [Ms.D thesis]. Xi'an, Northwest University. 2008. 10 (in Chinese)

Zhou D Q, Chen F, Cao P, et al. Analysis of fracture process zone in brittle rock subjected to shear-compressive loading. J. Cent. South Univ. Technol. 2005. 12(2): 209-213

(Edited by Hao Jie) 